\title{
Resolving the TorsinA Oligomerization Conundrum: The Glycan Hypothesis
}

\author{
Christian Fercher and Lucía F. Zacchi* \\ Australian Research Council (ARC), Training Centre for Biopharmaceutical Innovation, The University of Queensland, \\ St Lucia, QLD, Australia
}

TorsinA is a AAA+ ATPase involved in the severe neurological disease Early Onset Torsion Dystonia. Despite the impressive progress in the field in the recent years, the structural organization and function of this intriguing molecule is still not clear. One outstanding difference between torsinA and other AAA+ ATPases is that torsinA is a glycoprotein. TorsinA $N$-linked glycans impact torsinA biogenesis and subcellular localization. Here, we propose that torsinA glycans also modulate torsinA oligomerization properties. We used structural modeling to test this idea, and show that $\mathrm{N}$-linked glycans appear to restrict torsinA's ability to form closed homohexameric ring assemblies, and instead promote an open hexameric conformation that allows torsinA interaction with key cofactors required for ATP hydrolysis. This mechanism would make torsinA a prime example of Nature's sophisticated molecular glycoengineering.

Edited by:

Anastassios C. Papageorgiou, University of Turku, Finland

Reviewed by:

Nicolas Joly,

UMR 7592 Institut Jacques Monod (IJM), France

Michal Zolkiewski,

Kansas State University, United States

*Correspondence: Lucía F. Zacch

I.zacchi@uq.edu.au

Specialty section: This article was submitted to

Structural Biology,

a section of the journal

Frontiers in Molecular Biosciences

Received: 21 July 2020

Accepted: 14 September 2020

Published: 02 October 2020

Citation:

Fercher C and Zacchi LF (2020) Resolving the TorsinA Oligomerization Conundrum: The Glycan Hypothesis.

Front. Mol. Biosci. 7:585643.

doi: 10.3389/fmolb.2020.585643
Keywords: torsinA, glycans, AAA ATPase, modeling, structure

\section{INTRODUCTION}

TorsinA is an Endoplasmic Reticulum (ER) AAA+ ATPase associated with the development of the neurological disease Early-Onset Torsion Dystonia (EOTD) (Gonzalez-Alegre, 2019). TorsinA structure and function, and its role in EOTD onset are still controversial (Rose et al., 2015; Chase et al., 2017a). TorsinA is a rather unusual ATPase, as it lacks the AAA+ ATPase conserved hydrophobic pore loops involved in substrate unfolding and remodeling and the arginine finger required for ATP hydrolysis (Brown et al., 2014; Sosa et al., 2014; Demircioglu et al., 2016). In fact, the ATP hydrolysis activity of torsinA requires binding to the ER and Nuclear Envelope-type II transmembrane proteins LULL1 and LAP1, respectively (Zhao et al., 2013; Brown et al., 2014; Sosa et al., 2014). Further, AAA+ ATPases generally adopt hexameric conformations (Hanson and Whiteheart, 2005), but torsinA oligomerization status is still under debate. TorsinA has been proposed to form a homohexameric structure, and/or a heterohexameric structure with LULL1/LAP1, and/or a homopolymeric filament structure (Vander Heyden et al., 2009; Jungwirth et al., 2010; Zhao et al., 2013; Brown et al., 2014; Li et al., 2014; Sosa et al., 2014; Demircioglu et al., 2016, 2019; Chase et al., 2017a,b). It is unclear whether any of these oligomers reflect the physiological conformation of torsin $\mathrm{A}$, and if torsin $\mathrm{A}$ can dynamically transition from one to another.

Critically, the proposed polymeric structures for torsinA do not take into account one fundamental molecular characteristic of torsinA: that torsin A is a glycoprotein. Torsin A has two sites for $\mathrm{N}$-linked glycosylation located between the ATP binding and hydrolysis Walker domains (Ozelius et al., 1997; Figure 1). Both $N$-linked glycosylation sites are occupied in torsinA 
A ref|NP 000104.1|Homo sapiens gb|AAL05259.1|Rattus_norvegicus ref|NP_001272011.1|Macaca_fascicularis gb|EHA99927.1|Heterocephalus_glaber ref|NP_659133.1|Mus_musculus ref|NP_001092528.1|Bos_taurus $\mathrm{gb} \mid \mathrm{ABO} \mathbf{1 5 8 3 1 . 1 |}$ Sus_scrofa gb|ELK07271.1|Pteropus_alecto gb|ELK37394.1|Myotis_davidii gb|EPQ06418.1|Myotis_brandtii ref|NP_001025858.1|Gällus_gallus gb|KGL95740.1|Charadrius_vociferus gb|KQL60251.1|Amazona_aestiva gb|EMP34683.1|Chelonia_mydas gb|KQL62924.1|Alligator_mississippiensis gb|KGL74856.1|Tinamus guttatus gb|KF099059.1|Calypte_anna gb|EPY83322.1 Camelus_ferus gb|KF065615.1|Corvus_brachyrhynchos gb|KFU98537.1|Pterocles gutturalis gb|EOBO5953.1|Anas_platyrhynchos gb|KFW07428.1|Fulmarus_glacialis gb|KFP69633.1|Acanthisitta_chloris gb|KFV90707.1|Eurypyga_helias gb|KFW77252.1|Manacus_vitellinus gb|KF087149.1|Buceros_rhinoceros_silvestris gb|KFP58930.1|Cariama cristata gb|KFQ66499.1|Phaethon_lepturus gb|KFV02146.1| Tauraco_erythrolophus gb|KFU90618.1|Chaetura_pelagica gb|KFM12732.1|Aptenodytes_forsteri gb|KFV42802.1|Gavia_stellata gb|KFQ52059.1| Pelecanus_crispus gb|KFQ92951.1|Nipponia nippon gb|KFQ55958.1|Nestor_notabilis gb|KFP26894.1|Colius_striatus gb|KFQ39264.1|Mesitornis_unicolor gb|KFP85567.1|Apaloderma_vittatum gb|KFP19285.1| Egretta_garzetta gb|KFQ27457.1|Merops_nubicus gb|EMC77775.1|Columba_livia gb|KFW97297.1|Phalacrocorax carbo gb|KF012368.1|Balearica_regulorum_gibbericeps gb|KF082465.1|Cuculus_canorus ref|NP_001039096.1|Xenopus_tropicalis gb|KFQ07797.1|Haliaeetus alibicilla gb|KFZ58016.1|Caprimulgus_carolinensis gb|KFW65830.1|Pygoscelis_adeliae gb|KFZ59751.1|Podiceps_cristatus gb|KFQ14440.1|Leptosomus_discolor gb|ELV11789.1|Tupaia_chinensis gb|KFV64100.1|Picoides_pubescens

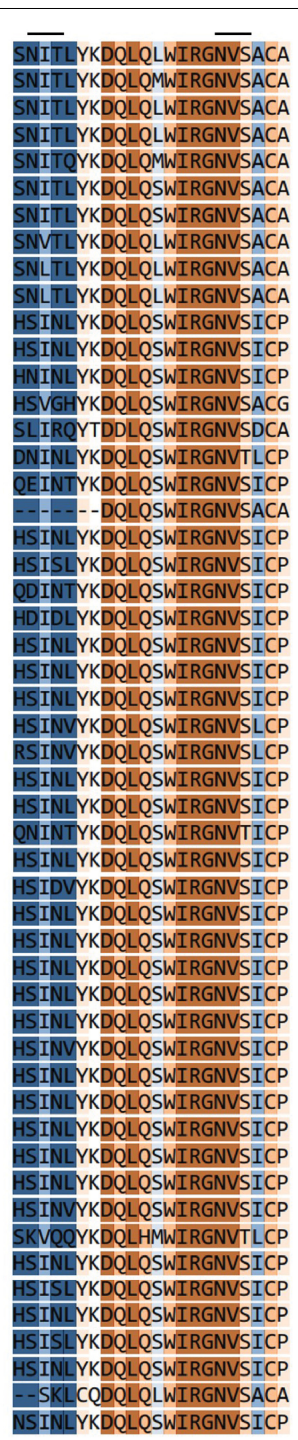

\begin{tabular}{|c|c|c|c|c|c|c|c|c|}
\hline 1 & 2 & 3 & 4 & 5 & 6 & 7 & 8 & 9 \\
\hline Variable & \multicolumn{4}{|c|}{ Average } & & \multicolumn{3}{c|}{ Conserved }
\end{tabular}

B

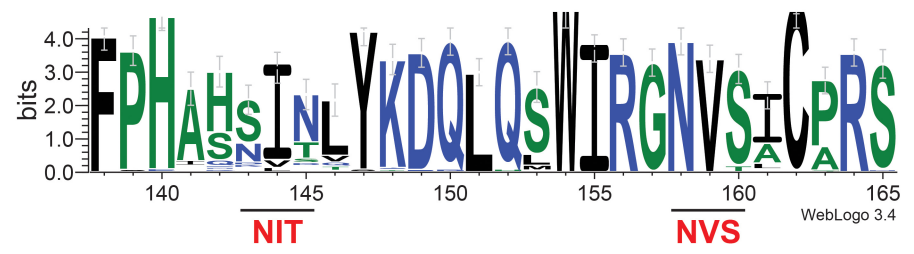

C

Walker B

sp 014656 TOR1A HUMAN 122 GGLNSDYVHLFVATLHFPHASNITLYKDOLOLWIRGNVSACARSIFIFDE sp|014657|TOR1B HUMAN 129 KGLKSNFVHLFVSTLHF PHEQKIKLYODQLOKWIRGNVSACANSVFIFDE sp Q5JU69 TOR2A_HUMAN 113 GGLRSPRVHHFSPVLHF PHPSHIERYKKDLKSWVQGNLTACGRSLFLFDE sp Q9H497 TOR3A_HUMAN 187 DGLMSDCVRMFIATFHF PHPKYVDLYKEQLMSQIRETQQLCHQTLFIFDE

FIGURE 1 | The second $N$-linked glycosylation site, but not the first, is conserved in torsinA homologs. (A) Human torsinA was aligned to 51 torsinA amino acid sequences spanning multiple species. Conservation scores were calculated using the ConSurf web server (https://consurf.tau.ac.il). (B) Sequence logo showing the conservation of the torsinA amino acid region containing the $\mathrm{N}^{143} \mathrm{IT}$ and $\mathrm{N}^{158} \mathrm{VS} \mathrm{N}$-linked glycosylation sites. The graphical comparison was obtained using Weblogo (http://weblogo.berkeley.edu/) (Crooks et al., 2004). (C) Alignment of human torsinA amino acid sequence with its homologs torsin1B, torsin2, and torsin3 (Uniprot identifiers and starting amino acid number are shown to the left of the sequences). The $\mathrm{N}^{143} \mathrm{IT}$ and $\mathrm{N}^{158} \mathrm{VS}$ N-linked glycosylation sites are highlighted in red and the Walker B ATP hydrolysis domain is indicated in black. The torsinA amino acids that are conserved in the homologs are shown in green. 
(Hewett et al., 2000, 2003; Kustedjo et al., 2000; Bragg et al., 2004; Gonzalez-Alegre and Paulson, 2004; Vander Heyden et al., 2011; Zacchi et al., 2014; Zhao et al., 2016). The $\mathrm{N}^{158}$ VS N-linked glycosylation site is highly conserved in torsin A homologs across different species (Figures 1A,B) and in the other three torsinA human homologs (Figure 1C; Ozelius et al., 1999; Zhu et al., 2008; Granata et al., 2009; Demircioglu et al., 2016), while the $\mathrm{N}^{143}$ IT glycosylation site is less conserved (Figure 1). $N$-linked glycans are heavily involved in protein folding and quality control (Aebi, 2013; Caramelo and Parodi, 2015; Zacchi et al., 2016). Indeed, torsin A requires at least one $N$-linked glycan for stability (Hewett et al., 2003; Zacchi et al., 2014). Interestingly, glycosylation at $\mathrm{N}^{158} \mathrm{VS}$ is selectively required to stabilize the EOTD-associated torsin $\mathrm{A} \Delta \mathrm{E}$ variant (Zacchi et al., 2014) and mutation of this site reverts the aberrant torsin $\mathrm{A} \Delta \mathrm{E}$ subcellular localization (Bragg et al., 2004). Therefore, $N$-linked glycans are key post-translational modifications for torsinA biogenesis. $\mathrm{N}$-linked glycans are bulky and hydrophilic molecules (Varki, 2017) and, in addition to their role in folding and quality control, $N$-linked glycans can restrict the formation of quaternary structures in proteins (Medus et al., 2017). This conformationshaping effect has been well documented for immunoglobulin $G$ (Nagae and Yamaguchi, 2012; Higel et al., 2016). Hence, $N$-linked glycans could also influence torsinA ability to form hexamers or filaments and interact with membranes and other proteins, impacting torsin A function.

\section{RESULTS AND DISCUSSION}

Modeling diverse oligomerization states of glycosylated torsinA supports the intriguing hypothesis that $N$-linked glycans play a fundamental structural and functional role in torsin $\mathrm{A}$ (Figure 2). To generate these models, we used the torsinALULL1 heterodimer crystal structure (PDB 5J1S) (Demircioglu et al., 2016). The torsinA-LULL1 structure displays torsinA without the transmembrane domain (TMD) and the ER lumenal (C-terminal) domain of LULL1 with the N-terminal residues that follow the TMD (Demircioglu et al., 2016). We modeled the position of the $\mathrm{N}$-linked glycans in torsinA based on this structure by attaching typical ER high mannose $N$-linked glycans at $\mathrm{Asn}^{143}$ and $\mathrm{Asn}^{158}$ (Hewett et al., 2000; Kustedjo et al., 2000; Aebi, 2013; Figure 2). In this model, the Asn ${ }^{158}$ glycan would be oriented parallel to the TMD, potentially facing the ER membrane while the $\mathrm{Asn}^{143}$ glycan would protrude from torsin A in a close to $90^{\circ}$ angle (Figure 2A). Due to their position in the folded protein, torsin A $N$-linked glycans would not impact heterodimerization with the LULL1/LAP1 cofactors (Figure 2A), as expected for this physiological interaction. However, structural modeling suggests that the Asn ${ }^{143}$ glycan would prevent homoand heterohexameric closed ring assemblies, as these glycans appear to face the constricted space of the central opening of the ring (Figures 2B,C, 3). Interestingly, this glycomolecular crowding would not be an issue for torsinB, torsinA's paralog (Ozelius et al., 1999; Hewett et al., 2004), since the $\mathrm{N}^{143} \mathrm{IT}$ glycosylation site is not conserved in torsinB (Figure 1C). Instead, torsinB contains a glycosylation site at $\mathrm{Asn}^{64}$, which is not oriented towards the inner ring but rather towards the outer perimeter (Figure 2D), potentially allowing for the formation of closed torsinB homohexameric rings (Figure 2D). The molecular crowding of $\mathrm{Asn}^{143} \mathrm{~N}$-linked glycans in this region of torsinA can be resolved when modeling torsin A homohexamers based on extended (Figures 2C, 3A) and open (Figure 3B) structural conformations of the homologous AAA ATPase Hsp104 (Lee et al., 2019). In these scenarios, the respective glycans would be accommodated by a slightly larger central opening and a pitch that results from a lock-washer-like conformation moving individual $\mathrm{Asn}^{143}$ residues out of plane. Similarly, glycan chains at $\mathrm{Asn}^{143}$ could be seamlessly accommodated by the larger central pore of torsinA filaments (Demircioglu et al., 2019; Figure 2E). However, Asn ${ }^{158}$ glycans would most likely prevent further polymerization due to geometrical restrictions that arise from interactions of torsin A molecules in consecutive turns of the ring which essentially block access to $\mathrm{Asn}^{158}$ (Figure 2E). Therefore, the presence of $\mathrm{N}$-linked glycosylation on $\mathrm{Asn}^{143}$ and Asn ${ }^{158}$ may promote assembly of torsinA into the proposed open homohexameric ring structures in vivo (Chase et al., 2017a,b). Intriguingly, this model would provide a basis to reconcile observations of homohexameric torsinA complexes with the fact that monomers need to be accessible for binding LULL1/LAP1 cofactors to exert their enzymatic function (Li et al., 2014; Chase et al., 2017a,b; Figure 3C). Based on our observations, we propose that fully glycosylated torsin A can only assemble into extended (Figure $\mathbf{3 A}$ ) or open (Figure 3B) hexameric structures upon binding ATP (Chase et al., 2017b). These complexes would be stabilized by the presence of the $\mathrm{Asn}^{143}$ and $\mathrm{Asn}^{158}$ glycans that prohibit closed ring structures or further polymerization into filaments. The transition between extended and open forms may be dynamic or could be triggered by interactions with the torsinA cofactor LULL1/LAP1 but, ultimately, an open conformation would be required to accommodate the torsinA-LULL1 heterodimer at the penultimate position of the complex (see Figure 3C for a model of the proposed transient heteroheptameric torsinA-LULL1 complex) (Chase et al., 2017a,b). Binding of the cofactor results in ATP hydrolysis, concomitant with ring dissassembly and loss of the torsin A subunit (Chase et al., 2017b).

Notably, glycosylation is not required for torsinA oligomerization, as bacterially expressed torsinA can assemble into hexamers and filaments (Sosa et al., 2014; Demircioglu et al., 2016, 2019) [although important caveats to the bacterial expression system that question the physiological relevance of these structures have been pointed out (Chase et al., 2017b; Demircioglu et al., 2019)]. Further, open ring conformations are naturally adopted by multiple other (cytosolic) AAA+ ATPases (Dong et al., 2019; Lee et al., 2019; Gates and Martin, 2020; Lopez et al., 2020), indicating that $N$-linked glycosylation is not required to generate open ring conformations. However, when present, torsin A $N$-linked glycans would ensure that this unusual ATPase maintains the open/extended oligomeric conformation required for LAP1/LULL1-dependent ATP hydrolysis by preventing the formation of closed ring assemblies. Therefore, torsin A $N$-linked glycans would play an essential role in modulating torsinA oligomerization and function. 
A

B
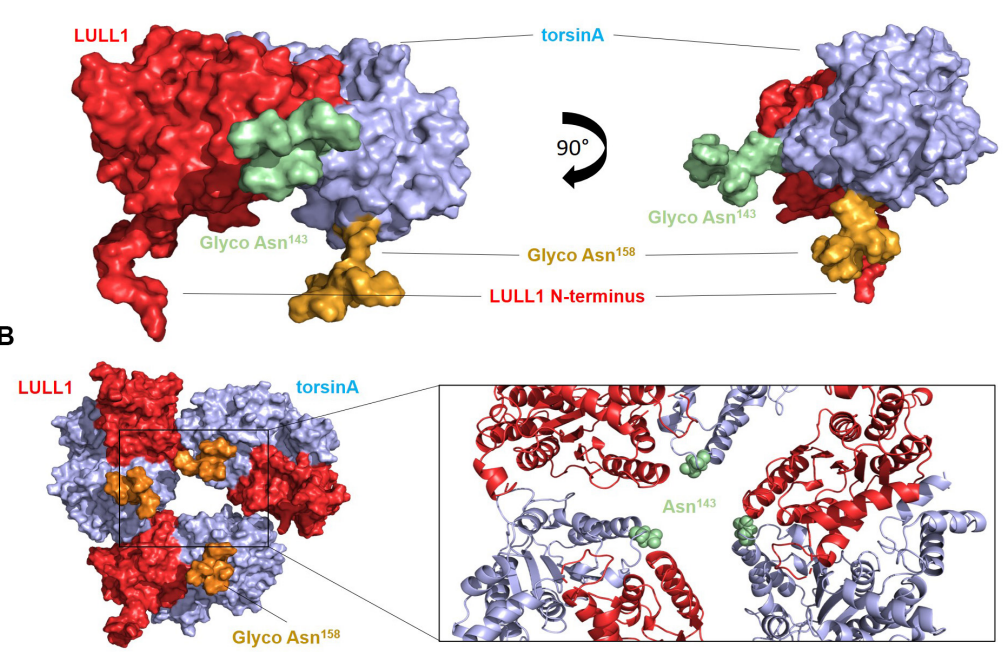

C

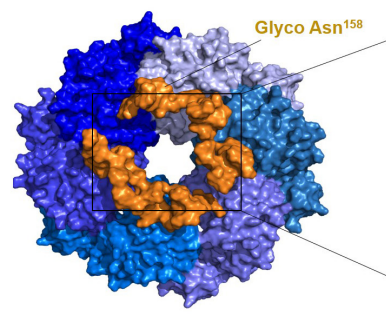

D

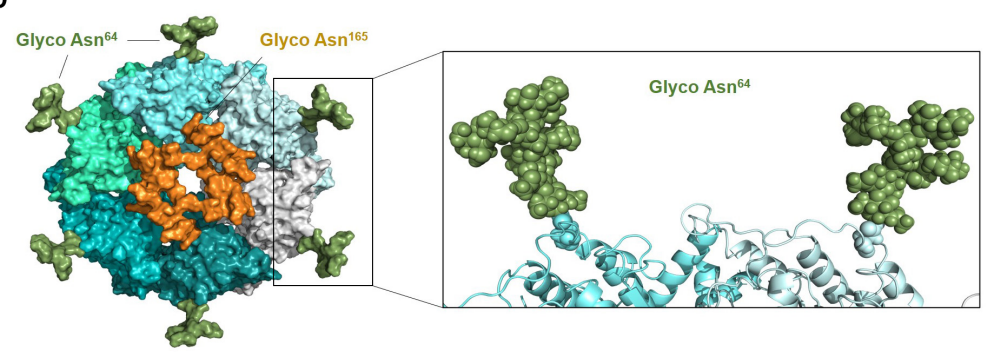

E

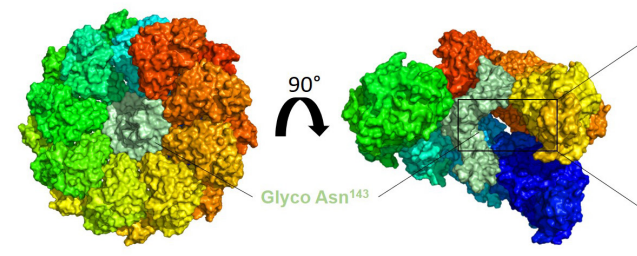

Asn ${ }^{1581165}$ glycosylation site (Torsin-1A/Torsin-1B))
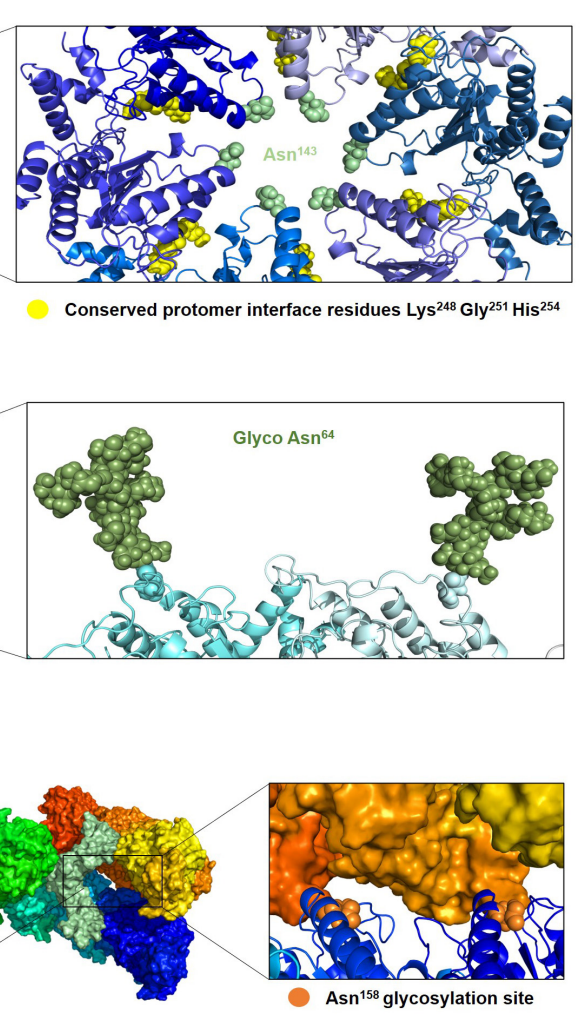

Asn ${ }^{158}$ glycosylation site

Asn $^{143}$ glycosylation site (Torsin-1A)
Schematic view
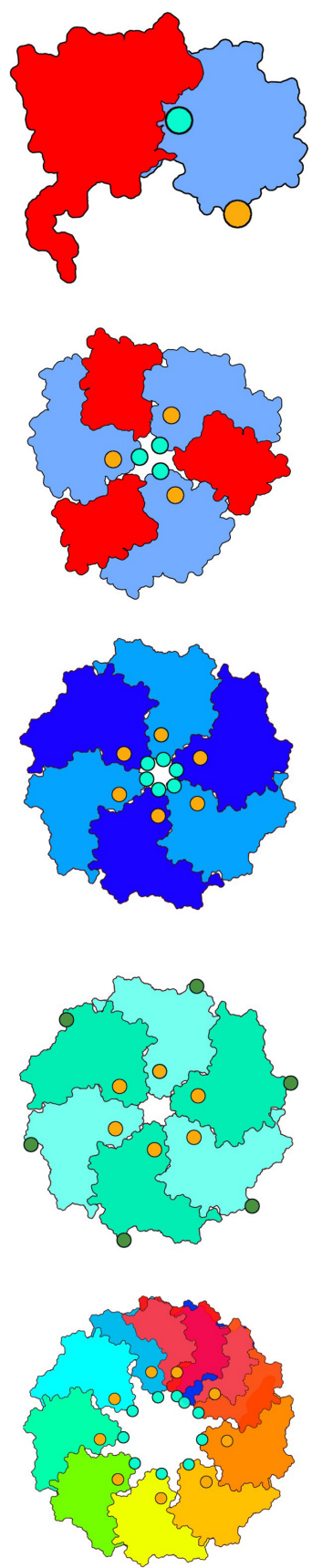

Asn ${ }^{164}$ glycosylation site (Torsin-1B)

FIGURE 2 | Oligomerization of glycosylated torsinA. (A) Typical ER high mannose glycans were attached to Asn ${ }^{143}$ (green) and Asn ${ }^{158}$ (orange) of torsinA (blue) using the high-resolution structure of the protein in complex with the C-terminal domain of its native interaction partner LULL1 (red) (PDB ID 5J1S) (Demircioglu et al., 2016). The N-terminal residues preceding LULL1 TMD are visible in the crystal structure. (B) Predicted heterohexameric model of glycosylated torsinA:LULL1 complex with the LULL1 N-terminus and Asn ${ }^{158} \mathrm{~N}$-linked glycans potentially facing the ER membrane. Generation of this model was only possible in the absence of Asn ${ }^{143} \mathrm{~N}$-linked glycans as these face the central opening of the ring which is not wide enough to accommodate three chains simultaneously. (C) Extended torsin A hexamer conformation showing the position of the Asn ${ }^{158}$ glycan. The amino acids involved in the conserved protomer interface are highlighted in yellow (Chase et al., 2017b). (D) Homohexameric glycosylated torsinB. N-linked glycans at Asn ${ }^{64}$ and Asn ${ }^{165}$ (equivalent to Asn ${ }^{158}$ in torsinA) are shown in green and orange, respectively. (E) Exemplary segment of a torsinA filament (PDB ID 6OIF) in rainbow colors to indicate individual monomers. The middle structure is presented in open side view to illustrate the internal arrangement of the $\mathrm{Asn}^{143} \mathrm{~N}$-linked glycan chains. The position of two consecutive Asn ${ }^{158}$ glycosylation sites between individual turns of the filament are indicated as orange spheres. Structures were modeled as follows. TorsinA and torsinB (Uniprot ID O14656 and O14657) were in silico 
FIGURE 2 | Continued

glycosylated with high mannose N-linked glycans using CHARMM-GUI Glycan Modeler (Park et al., 2019). Three copies of the torsinA-LULL1 glycoprotein complex were used to construct a heterohexameric model based on the closed conformations of Hsp104 (6N8T) and ClpC (3PXI), which represent the closest torsinA homologs in terms of sequence identity for which hexameric ring structures are currently available. Both complexes were virtually identical and those based on $6 \mathrm{~N} 8 \mathrm{~T}$ were subsequently used for all models. Structures were energy minimized to resolve minor sterical clashes at the subunit interfaces and to create glycan conformations compatible with a hexameric assembly employing the YASARA force field (Krieger et al., 2009). The homology model of torsinB was generated with Modeler (Webb and Sali, 2016) using torsinA as a template (67\% sequence identity). Glycosylation and complex building were done analogous to torsinA. Alignments and figures were prepared using PyMOL (Schrödinger). Schematic views of the oligomers are shown on the right, with the green and orange circles indicating the position of the $\mathrm{Asn}^{143}$ and $\mathrm{Asn}^{158} \mathrm{~N}$-linked glycans, respectively.

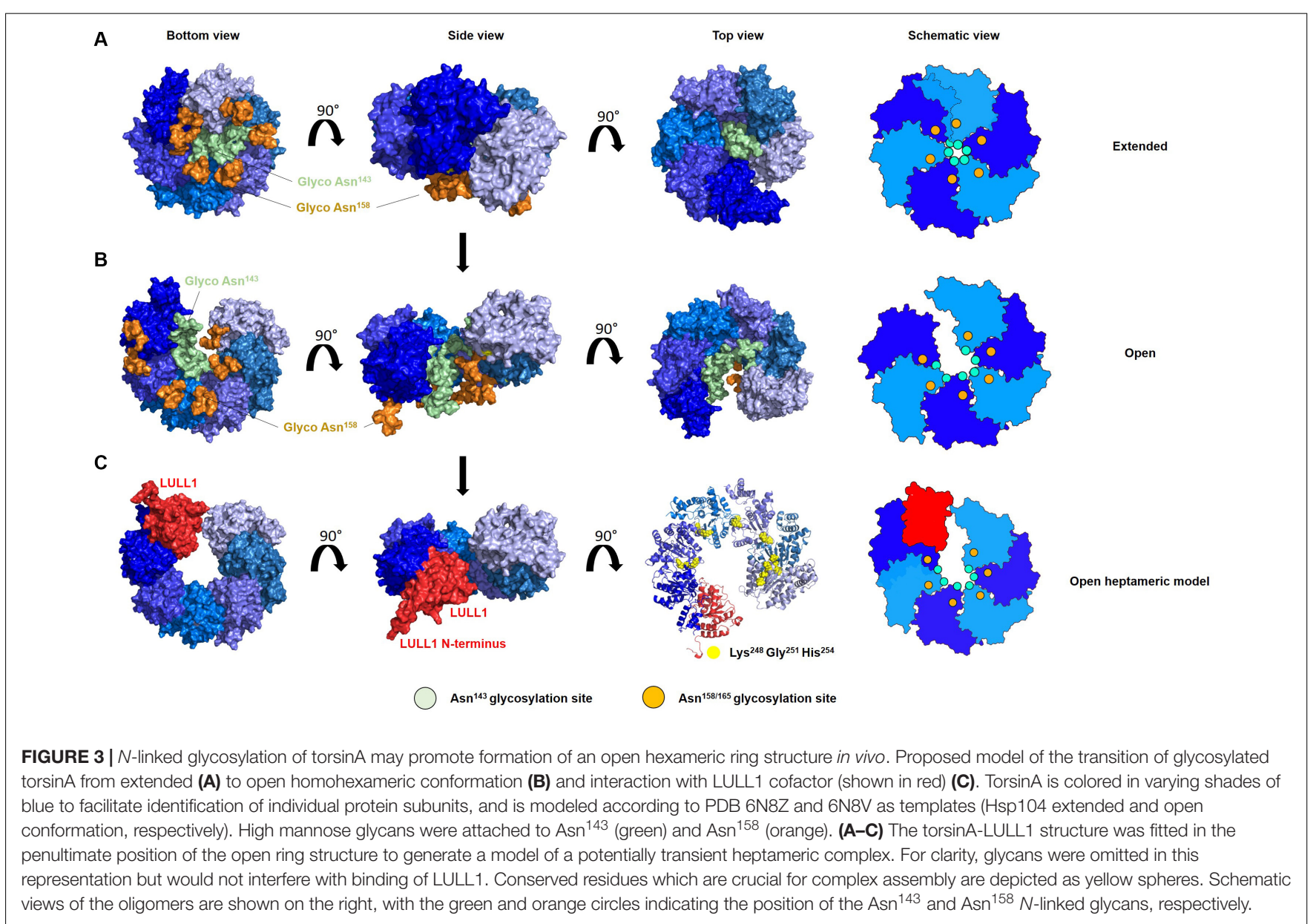

The potential impact of $N$-linked glycans on torsinA oligomerization would add another layer of complexity into the regulation of torsinA function. In this context, genetic or environmental factors that lead to defects in protein translocation into the ER, in protein glycosylation, or in glycan-dependent folding or quality control would impact torsin A ability to form closed or open hexamers and, in turn, its ability to interact with its cofactors. Considering the delicate equilibrium that governs ER homeostasis, how torsin A $N$-linked glycosylation is sensitive to redox changes and to defects in certain ER chaperones and enzymes (Zacchi et al., 2014), and how accessibility to these enzymes and chaperones could vary throughout cell development or due to cell type or subcompartment localization (Shenkman and Lederkremer, 2019; Almeida and Amaral, 2020), it is tempting to speculate that $N$-linked glycans offer torsin A the key to a dynamic conformational and functional molecular polymorphism.

$N$-linked glycans are highly diverse structures that play myriad of functional roles in the cell (Varki, 2017). $N$-linked glycans are usually studied in the context of protein quality control during folding and biogenesis, of genetic diseases, and due to their role in immunological responses and microbial pathogenesis. However, it is becoming increasingly clear that the occupancy and structural heterogeneity of the glycans play fundamental structural and physiological roles (Higel et al., 2016; Zacchi and Schulz, 2016; Medus et al., 2017). Here, we highlight the key function of $N$-linked glycans in shaping the conformation and structure of protein complexes (Medus et al., 2017), and hypothesize that their presence or absence dramatically impact torsin A oligomerization by introducing sterical restrictions. The 
last decades have seen phenomenal advances in protein and glycan structural characterization technologies. The combination of both fields of studies will not only unravel the quaternary structure of this fascinating protein, but will also provide an exciting new magnifying glass into biology.

\section{DATA AVAILABILITY STATEMENT}

Publicly available datasets were analyzed in this study. This data can be found here: All datasets used are available in https://www. rcsb.org/. The specific datasets used in this work are: PDB ID 5J1S, PDB ID 6OIF, PDB ID 6N8T, PDB ID 3PXI, PDB ID 6N8Z, and PDB ID 6N8V.

\section{AUTHOR CONTRIBUTIONS}

CF and LZ were involved in all aspects of this work regarding conception and design, data analysis and interpretation, writing

\section{REFERENCES}

Aebi, M. (2013). N-linked protein glycosylation in the ER. Biochim. Biophys. Acta 1833, 2430-2437. doi: 10.1016/j.bbamcr.2013.04.001

Almeida, C., and Amaral, M. D. (2020). A central role of the endoplasmic reticulum in the cell emerges from its functional contact sites with multiple organelles. Cell. Mol. Life Sci. doi: 10.1007/s00018-020-03523-w [Epub ahead of print].

Bragg, D. C., Kaufman, C. A., Kock, N., and Breakefield, X. O. (2004). Inhibition of N-linked glycosylation prevents inclusion formation by the dystonia-related mutant form of torsinA. Mol. Cell. Neurosci. 27, 417-426. doi: 10.1016/j.mcn. 2004.07.009

Brown, R. S., Zhao, C., Chase, A. R., Wang, J., and Schlieker, C. (2014). The mechanism of Torsin ATPase activation. Proc. Natl. Acad. Sci. U.S.A. 111, E4822-E4831. doi: 10.1073/pnas.14152 71111

Caramelo, J. J., and Parodi, A. J. (2015). A sweet code for glycoprotein folding. FEBS Lett. 589, 3379-3387. doi: 10.1016/j.febslet.2015.07.021

Chase, A. R., Laudermilch, E., and Schlieker, C. (2017a). Torsin ATPases: harnessing dynamic instability for function. Front. Mol. Biosci. 4:29. doi: 10. 3389/fmolb.2017.00029

Chase, A. R., Laudermilch, E., Wang, J., Shigematsu, H., Yokoyama, T., and Schlieker, C. (2017b). Dynamic functional assembly of the Torsin AAA+ ATPase and its modulation by LAP1. Mol. Biol. Cell. 28, 2765-2772. doi: 10. 1091/mbc.E17-05-0281

Crooks, G. E., Hon, G., Chandonia, J.-M., and Brenner, S. E. (2004). WebLogo: a sequence logo generator. Genome Res. 14, 1188-1190. doi: 10.1101/gr.849004

Demircioglu, F. E., Sosa, B. A., Ingram, J., Ploegh, H. L., and Schwartz, T. U. (2016). Structures of TorsinA and its disease-mutant complexed with an activator reveal the molecular basis for primary dystonia. eLife 5:e17983. doi: 10.7554/ eLife.17983

Demircioglu, F. E., Zheng, W., McQuown, A. J., Maier, N. K., Watson, N., Cheeseman, I. M., et al. (2019). The AAA + ATPase TorsinA polymerizes into hollow helical tubes with 8.5 subunits per turn. Nat. Commun. 10:3262. doi: 10.1038/s41467-019-11194-w

Dong, Y., Zhang, S., Wu, Z., Li, X., Wang, W. L., Zhu, Y., et al. (2019). Cryo-EM structures and dynamics of substrate-engaged human $26 \mathrm{~S}$ proteasome. Nature 565, 49-55. doi: 10.1038/s41586-018-0736-4

Gates, S. N., and Martin, A. (2020). Stairway to translocation: AAA+ motor structures reveal the mechanisms of ATP-dependent substrate translocation. Protein Sci. 29, 407-419. doi: 10.1002/pro. 3743

Gonzalez-Alegre, P. (2019). Advances in molecular and cell biology of dystonia: focus on torsinA. Neurobiol. Dis. 127, 233-241. doi: 10.1016/j.nbd.2019.03.007 and editing of the manuscript, and made the figures. CF performed the structural modeling. Both authors contributed to the article and approved the submitted version.

\section{FUNDING}

This work was funded by the Australian Research Council Industrial Transformation Training Centre IC160100027. LZ holds a Promoting Women Fellowship from the University of Queensland.

\section{ACKNOWLEDGMENTS}

We are grateful to Prof. Alan Rowan and Prof. Stephen Mahler from the University of Queensland for their support and to Prof. Jeffrey Brodsky from the University of Pittsburgh for suggestions and advise.

Gonzalez-Alegre, P., and Paulson, H. L. (2004). Aberrant cellular behavior of mutant torsinA implicates nuclear envelope dysfunction in DYT1 dystonia. J. Neurosci. 24, 2593-2601. doi: 10.1523/jneurosci.4461-03.2004

Granata, A., Schiavo, G., and Warner, T. T. (2009). TorsinA and dystonia: from nuclear envelope to synapse. J. Neurochem. 109, 1596-1609. doi: 10.1111/j. 1471-4159.2009.06095.x

Hanson, P. I., and Whiteheart, S. W. (2005). AAA+ proteins: have engine, will work. Nat. Rev. Mol. Cell. Biol. 6, 519-529. doi: 10.1038/nrm1684

Hewett, J., Gonzalez-Agosti, C., Slater, D., Ziefer, P., Li, S., Bergeron, D., et al. (2000). Mutant torsinA, responsible for early-onset torsion dystonia, forms membrane inclusions in cultured neural cells. Hum. Mol. Genet. 9, 1403-1413. doi: $10.1093 / \mathrm{hmg} / 9.9 .1403$

Hewett, J., Ziefer, P., Bergeron, D., Naismith, T., Boston, H., Slater, D., et al. (2003). Torsin A in PC12 cells: localization in the endoplasmic reticulum and response to stress. J. Neurosci. Res. 72, 158-168. doi: 10.1002/jnr.10567

Hewett, J. W., Kamm, C., Boston, H., Beauchamp, R., Naismith, T., Ozelius, L., et al. (2004). TorsinB-perinuclear location and association with torsinA. J. Neurochem. 89, 1186-1194. doi: 10.1111/j.1471-4159.2004.02404.x

Higel, F., Seidl, A., Sorgel, F., and Friess, W. (2016). N-glycosylation heterogeneity and the influence on structure, function and pharmacokinetics of monoclonal antibodies and Fc fusion proteins. Eur. J. Pharm. Biopharm. 100, 94-100. doi: 10.1016/j.ejpb.2016.01.005

Jungwirth, M., Dear, M. L., Brown, P., Holbrook, K., and Goodchild, R. (2010). Relative tissue expression of homologous torsinB correlates with the neuronal specific importance of DYT1 dystonia-associated torsinA. Hum. Mol. Genet. 19, 888-900. doi: 10.1093/hmg/ddp557

Krieger, E., Joo, K., Lee, J., Lee, J., Raman, S., Thompson, J., et al. (2009). Improving physical realism, stereochemistry, and side-chain accuracy in homology modeling: four approaches that performed well in CASP8. Proteins 77(Suppl. 9), 114-122. doi: 10.1002/prot.22570

Kustedjo, K., Bracey, M. H., and Cravatt, B. F. (2000). Torsin A and its torsion dystonia-associated mutant forms are lumenal glycoproteins that exhibit distinct subcellular localizations. J. Biol. Chem. 275, 27933-27939.

Lee, S., Roh, S. H., Lee, J., Sung, N., Liu, J., and Tsai, F. T. F. (2019). CryoEM structures of the Hsp104 protein disaggregase captured in the ATP conformation. Cell. Rep. 26, 29.e3-36.e3. doi: 10.1016/j.celrep.2018.12.037

Li, H., Wu, H.-C., Liu, Z., Zacchi, L. F., Brodsky, J. L., and Zolkiewski, M. (2014). Intracellular complexes of the early-onset torsion dystonia-associated AAA+ ATPase TorsinA. SpringerPlus 3:743. doi: 10.1186/2193-1801-3-743

Lopez, K. E., Rizo, A. N., Tse, E., Lin, J., Scull, N. W., Thwin, A. C., et al. (2020). Conformational plasticity of the ClpAP AAA+ protease couples protein unfolding and proteolysis. Nat. Struct. Mol. Biol. 27, 406-416. doi: 10.1038/ s41594-020-0409-5 
Medus, M. L., Gomez, G. E., Zacchi, L. F., Couto, P. M., Labriola, C. A., Labanda, M. S., et al. (2017). N-glycosylation triggers a dual selection pressure in eukaryotic secretory proteins. Sci. Rep. 7:8788. doi: 10.1038/s41598-017-09 173-6

Nagae, M., and Yamaguchi, Y. (2012). Function and 3D structure of the N-glycans on glycoproteins. Int. J. Mol. Sci. 13, 8398-8429. doi: 10.3390/ijms1307 8398

Ozelius, L. J., Hewett, J. W., Page, C. E., Bressman, S. B., Kramer, P. L., Shalish, C., et al. (1997). The early-onset torsion dystonia gene (DYT1) encodes an ATP-binding protein. Nat. Genet. 17, 40-48. doi: 10.1038/ng0997-40

Ozelius, L. J., Page, C. E., Klein, C., Hewett, J. W., Mineta, M., Leung, J., et al. (1999). The TOR1A (DYT1) gene family and its role in early onset torsion dystonia. Genomics 62, 377-384. doi: 10.1006/geno.1999.6039

Park, S. J., Lee, J., Qi, Y., Kern, N. R., Lee, H. S., Jo, S., et al. (2019). CHARMMGUI Glycan Modeler for modeling and simulation of carbohydrates and glycoconjugates. Glycobiology 29, 320-331. doi: 10.1093/glycob/cwz003

Rose, A. E., Brown, R. S., and Schlieker, C. (2015). Torsins: not your typical AAA+ ATPases. Crit. Rev. Biochem. Mol. Biol. 50, 532-549. doi: 10.3109/10409238. 2015.1091804

Shenkman, M., and Lederkremer, G. Z. (2019). Compartmentalization and selective tagging for disposal of misfolded glycoproteins. Trends Biochem. Sci. 44, 827-836. doi: 10.1016/j.tibs.2019.04.012

Sosa, B. A., Demircioglu, F. E., Chen, J. Z., Ingram, J., Ploegh, H. L., and Schwartz, T. U. (2014). How lamina-associated polypeptide 1 (LAP1) activates torsin. eLife 3:e03239. doi: 10.7554/eLife.03239

Vander Heyden, A. B., Naismith, T. V., Snapp, E. L., and Hanson, P. I. (2011). Static retention of the lumenal monotopic membrane protein torsinA in the endoplasmic reticulum. EMBO J. 30, 3217-3231. doi: 10.1038/emboj.2011.233

Vander Heyden, A. B., Naismith, T. V., Snapp, E. L., Hodzic, D., and Hanson, P. I. (2009). LULL1 retargets TorsinA to the nuclear envelope revealing an activity that is impaired by the DYT1 dystonia mutation. Mol. Biol. Cell. 20, 2661-2672. doi: 10.1091/mbc.E09-01-0094

Varki, A. (2017). Biological roles of glycans. Glycobiology 27, 3-49. doi: 10.1093/ glycob/cww086

Webb, B., and Sali, A. (2016). Comparative protein structure modeling using MODELLER. Curr. Protoc. Bioinformatics 54, 5.6.1-5.6.37. doi: 10.1002/cpbi.3
Zacchi, L. F., Caramelo, J. J., McCracken, A. A., and Brodsky, J. L. (2016). "Endoplasmic reticulum associated degradation and protein quality control," in The Encyclopedia of Cell Biology, 1st Edn, ed. R. B. A. P. Stahl (Waltham, MA: Academic Press), 596-611. doi: 10.1016/b978-0-12-394447-4.10072-0

Zacchi, L. F., and Schulz, B. L. (2016). N-glycoprotein macroheterogeneity: biological implications and proteomic characterization. Glycoconj. J. 33, 359376. doi: 10.1007/s10719-015-9641-3

Zacchi, L. F., Wu, H. C., Bell, S. L., Millen, L., Paton, A. W., Paton, J. C., et al. (2014). The BiP molecular chaperone plays multiple roles during the biogenesis of torsinA, an AAA+ ATPase associated with the neurological disease earlyonset torsion dystonia. J. Biol. Chem. 289, 12727-12747. doi: 10.1074/jbc.M113. 529123

Zhao, C., Brown, R. S., Chase, A. R., Eisele, M. R., and Schlieker, C. (2013). Regulation of Torsin ATPases by LAP1 and LULL1. Proc. Natl. Acad. Sci. U.S.A. 110, E1545-E1554. doi: 10.1073/pnas.13006 76110

Zhao, C., Brown, R. S., Tang, C. H., Hu, C. C., and Schlieker, C. (2016). Sitespecific proteolysis mobilizes TorsinA from the membrane of the endoplasmic reticulum (ER) in response to ER stress and B cell stimulation. J. Biol. Chem. 291, 9469-9481. doi: 10.1074/jbc.M115.709337

Zhu, L., Wrabl, J. O., Hayashi, A. P., Rose, L. S., and Thomas, P. J. (2008). The torsin-family AAA+ protein OOC-5 contains a critical disulfide adjacent to Sensor-II that couples redox state to nucleotide binding. Mol. Biol. Cell. 19, 3599-3612. doi: 10.1091/mbc.e08-010015

Conflict of Interest: The authors declare that the research was conducted in the absence of any commercial or financial relationships that could be construed as a potential conflict of interest.

Copyright (C) 2020 Fercher and Zacchi. This is an open-access article distributed under the terms of the Creative Commons Attribution License (CC BY). The use, distribution or reproduction in other forums is permitted, provided the original author(s) and the copyright owner(s) are credited and that the original publication in this journal is cited, in accordance with accepted academic practice. No use, distribution or reproduction is permitted which does not comply with these terms. 